\title{
Territorialidade e formação do servidor no contexto da metrópole
}

\section{RESUMO}

Andrea Traub

atraub@alunos.uttpr.edu.br

Universidade Tecnológica Federal do

Paraná, Curitiba, Paraná, Brasil

Ana Paula Myszczuk

anap@utfpr.edu.br

Universidade Tecnológica Federal do

Paraná, Curitiba, Paraná, Brasil
O presente artigo tem por objetivo apresentar os arranjos institucionais e atual cenário da Região Metropolitana de Curitiba, assim como, analisar se uma Escola Metropolitana de Administração Pública seria capaz de oportunizar ao servidor uma formação adequada e com vistas a uma atuação integrada, com visão crítica e ampla acerca dos significados de uma política pública. Para tanto, a metodologia utilizada é descritiva e exploratória, com abordagem qualitativa. Sua fundamentação se deu por meio de estudo de caso e a fonte de coleta de dados, pela utilização de documentos. A Escola analisada é a mantida pelo Instituto Municipal de Administração Pública, autarquia da Prefeitura Municipal de Curitiba, por meio do Programa de Integração e Compartilhamento de Conhecimento entre Servidores Municipais de Curitiba e Região Metropolitana. Os principais resultados demonstram que a atuação de uma Escola de Administração Pública é de extrema importância, dada a abrangência metropolitana e a necessidade de integração entre os municípios da região.

PALAVRAS-CHAVE:Gestão do território. Formação de servidores. Escola de Administração Pública. 


\section{INTRODUÇÃO}

O território metropolitano contempla interfaces de ordem política, econômica e institucional, agrega relações que englobam as funções locais, regionais, nacionais e globais e tem seu crescimento relacionado com a implementação adequada de estratégias e políticas de desenvolvimento. Nesta perspectiva, o maior:

[...] desafio do estado, que constitui o ente federativo responsável pela criação e gestão das RMs, vem sendo a criação de arranjos de gestão compartilhada para abarcar as complexas relações transescalares que mediam os espaços metropolitanos brasileiros (IPEA, 2015a, p. 7).

A Região Metropolitana (RM) de Curitiba é marcada por desigualdades e contradições entre os municípios que evidenciam a pobreza, a exclusão e a segregação socioeconômica. A sua metrópole é o lugar em que acontece a dinâmica econômica e a concentração de riqueza, possuindo uma posição de centro de decisão, de poder e de gestão. A expansão de Curitiba consolidou o seu entorno, entretanto, não fortaleceu os municípios vizinhos do ponto de vista econômico. Com relação aos municípios mais afastados, nota-se, também, acentuada fragmentação e fragilização socioeconômica devido à pouca integração com a metrópole.

A Constituição Federal de 1988, em seu artigo 3ำ, inciso III, constitui como objetivos fundamentais "[...] erradicar a pobreza e a marginalização e reduzir as desigualdades sociais e regionais" (BRASIL, 1988). Partindo dessa premissa e tendo como base a responsabilidade da gestão municipal na formulação e na execução das políticas públicas, cuja função é modificar uma realidade, torna-se fundamental a formação e o desenvolvimento profissional dos servidores municipais. Um servidor com formação adequada terá condições plenas de potencializar a operacionalização e a reflexão sob tal política, visando à transformação de uma determinada realidade.

O processo de fortalecimento das administrações municipais e a construção de uma governança integrada para o desenvolvimento regional tornam-se imprescindíveis para a consolidação da gestão do território por meio dos arranjos institucionais estabelecidos. Assim, apresentam-se os arranjos e o atual cenário da RM de Curitiba, bem como, a importância da formação e desenvolvimento profissional dos servidores municipais. Neste sentido, analisa-se se uma Escola Metropolitana de Administração Pública seria capaz de oportunizar ao servidor uma formação adequada com vistas a uma atuação integrada, com visão crítica e ampla acerca dos significados de uma política pública.

Com relação à metodologia utilizada, trata-se de pesquisa aplicada, classificada como descritiva e exploratória, com abordagem qualitativa, tendo em vista o aprofundamento das informações e a busca de resultados mais próximos da realidade. Sua fundamentação se deu por meio de estudo de caso, consistindo em uma investigação aprofundada do tema em seus aspectos específicos e suas decorrências. A fonte para a coleta de dados se deu pela utilização de documentos, caracterizando-se por uma pesquisa documental. Neste levantamento, foram levados em consideração os traços subjetivos e particularizados dos dados analisados. 
Este artigo está dividido em seis partes, sendo esta introdução a primeira. Na segunda parte, aborda-se a legislação de referência e os arranjos institucionais para a gestão metropolitana. Na terceira parte, o cenário atual da RM de Curitiba considerando os aspectos espacial, econômico e social. Na quarta parte, a formação profissional dos servidores municipais e a apresentação do Programa de Integração e Compartilhamento de Conhecimento entre Servidores Municipais de Curitiba e Região Metropolitana, desenvolvido pelo Instituto Municipal de Administração Pública. Na última parte, as considerações finais.

\section{LEGISLAÇÃO E ARRANJOS INSTITUCIONAIS DA REGIÃO METROPOLITANA DE CURITIBA}

A Região Metropolitana (RM) de Curitiba foi criada pela Lei Complementar Federal no 14, de 8 de junho de 1973, que instituiu as primeiras regiões metropolitanas brasileiras. Com a Constituição Federal de 1988, foi estabelecida a participação dos estados na gestão das funções públicas de interesse comum, conforme dispõe o artigo 25, parágrafo 3 :

Os Estados poderão, mediante lei complementar, instituir regiões metropolitanas, aglomerações urbanas e microrregiões, constituídas por agrupamentos de municípios limítrofes, para integrar a organização, o planejamento e a execução de funções públicas de interesse comum (BRASIL, 1988).

Sendo assim, na década de 1990, acontecem os primeiros desmembramentos metropolitanos e a inclusão de novos municípios na RM de Curitiba. Os limites geográficos do território são alterados, a partir do ano de 1994, por meio de legislações estaduais. No quadro 1, observam-se os quatorze municípios da composição original, os municípios desmembrados e aqueles incluídos por legislação.

Quadro 1 -Composição da Região Metropolitana de Curitiba ${ }^{1}$

\begin{tabular}{|c|c|c|}
\hline COMPOSIÇÃO ORIGINAL & $\begin{array}{c}\text { MUNICÍPIOS } \\
\text { DESMEMBRADOS } \\
(\mathbf{1 9 9 0 / 1 9 9 2 )}\end{array}$ & $\begin{array}{c}\text { MUNICÍPIOS INCLUÍDOS POR } \\
\text { LEGISLAÇÃO ESTADUAL (1994-2011) }\end{array}$ \\
\hline Almirante Tamandaré & & Adrianópolis (2) \\
\hline Araucária & & Agudos do Sul (3) \\
\hline Balsa Nova & Tunas do Paraná & Campo do Tenente (5) \\
\hline Bocaiúva do Sul & & Campo Magro (2) \\
\hline Campina Grande do Sul & & Cerro Azul (1) \\
\hline Campo Largo & & Doutor Ulysses (1) \\
\hline Colombo & & Lapa (4) \\
\hline Contenda & Quitandinha (1) \\
\hline Curitiba & Fazenda Rio Grande & Rio Negro (5) \\
\hline Mandirituba & Pinhais & Tijucas do Sul (1) \\
\hline Piraquara & & \\
\hline
\end{tabular}

\footnotetext{
Pásinòtả̧: Lei Estadual no 11.027/1994 (1); Lei Estadual no 11.096/1995 (2); Lei Estadual no 12.125/1998 (3); Lei Estadual no 13.512/2002 (4); e Lei Complementar Estadual no 139/2011 (5).
} 


\begin{tabular}{|c|c|c|}
\hline Quatro Barras & & \\
\hline Rio Branco do Sul & Itaperuçu & \\
\hline São José dos Pinhais & & \\
\hline
\end{tabular}

Fonte: Elaborado pelas autoras (2016).

Os arranjos institucionais da gestão metropolitana têm a finalidade de controlar e planejar o funcionamento da região, garantir as articulações entre o poder público e os diferentes atores sociais, além de definir o desenvolvimento das questões metropolitanas no que se refere a Funções Públicas de Interesse Comum (FPIC). Atualmente, são compostos pelas seguintes instâncias de gestão: “i) Coordenação da Região Metropolitana de Curitiba (COMEC), no âmbito do Poder Público Estadual; ii) Secretaria Municipal de Assuntos Metropolitanos (SMAM) de Curitiba, no âmbito da administração direta do poder público municipal; e iii) Associação dos Municípios da Região Metropolitana de Curitiba (ASSOMEC), no âmbito supra municipal, de representação do poder público municipal dos 29 municípios que integram a RM de Curitiba" (KORNIN; CARMO, 2013, p. 91).

A COMEC ${ }^{2}$ é uma autarquia indireta do Poder Executivo Estadual, vinculada à Secretaria de Desenvolvimento Urbano (SEDU), responsável pelas questões técnicas e operacionais da gestão metropolitana. Seus principais instrumentos de gestão são: Controle de Organização Territorial ${ }^{3}$; Sistema Integrado de Gestão dos Mananciais ${ }^{4}$; Gerenciamento do Sistema de Transporte Coletivo5; e Câmara Técnica de Sistema Viário Metropolitano. Também articula as seguintes instâncias associadas: Secretaria Administrativa; Conselho Deliberativo; Conselho Consultivo; e Conselho Gestor dos Mananciais da RM de Curitiba.

A SMAM ${ }^{6}$ é um órgão específico da Prefeitura Municipal de Curitiba (PMC), que tem por missão "Implementar políticas públicas de desenvolvimento do Município de Curitiba, em conjunto com os demais municípios da Região Metropolitana de Curitiba (RMC), viabilizando ações de interesse comum, através do assessoramento e desenvolvimento de programas e projetos, promovendo a integração regional" (CURITIBA, 2016). Dentre as atribuições estão a coordenação das ações de Curitiba junto aos demais municípios da RM e o apoio por meio da transferência do conhecimento técnico em programas e projetos de desenvolvimento urbano, além da articulação com as demais administrações municipais, entidades metropolitanas e com o Governo do Estado do Paraná.

A ASSOMEC foi instituída no ano de 1982 e representa a totalidade dos prefeitos da região metropolitana no Conselho Deliberativo da COMEC. É composta por uma Diretoria, Conselho Fiscal e Conselho Consultivo. Segundo Kornin e Carmo (2013, p. 91), “[...] é o organismo criado pelos prefeitos

2Lei Estadual no 6.517/1974.

${ }^{3}$ Lei Federal nำ6.766/1979.

${ }^{4}$ Lei Estadual no 12.248/1998.

${ }^{5}$ Decreto Estadual № 1.660/1992. Página | 371

${ }^{6}$ Lei Municipal ํㅜ 857/2005. 
municipais para promover a articulação dos governos locais com o governo estadual para a gestão metropolitana".

\title{
ESTATUTO DA METRÓPOLE
}

O Estatuto da Metrópole (EM), instituído pela Lei Federal no 13.089, de 12 de janeiro de 2015, tem o objetivo de promover ações, por meio das FPICs, de integração entre os municípios que formam uma RM, em conjunto com os governos estaduais e governo federal. Conforme seu artigo 1:

\begin{abstract}
Estabelece diretrizes gerais para o planejamento, a gestão e a execução das funções públicas de interesse comum em regiões metropolitanas e em aglomerações urbanas instituídas pelos Estados, normas gerais sobre o plano de desenvolvimento urbano integrado e outros instrumentos de governança interfederativa, e critérios para o apoio da União a ações que envolvam governança interfederativa no campo do desenvolvimento urbano, com base nos

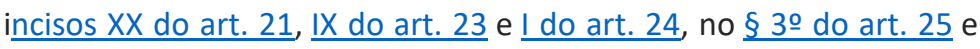
no art. 182 da Constituição Federal(BRASIL, 2015).
\end{abstract}

Assim, o Estado e os municípios que integram uma RM devem promover a governança interfederativa, respeitando alguns princípios e diretrizes específicas. Tal governança deve acontecer com a participação da população, com órgãos colegiados de política urbana, debates, audiências, consultas públicas, conferências, programas e projetos de desenvolvimento urbano. Dentre os instrumentos, estão o Plano de Desenvolvimento Urbano Integrado (PDUI); consórcios públicos; convênios de cooperação; contratos de gestão; e parcerias público-privadas.

Segundo o EM, as FPICs são políticas públicas cuja realização por parte de um município, isoladamente, é inviável ou causa impacto em municípios limítrofes. Envolve funções específicas de forma integrada e não devem ser confundidas com serviços públicos. A gestão das FPICs na RM de Curitiba é organizada pela COMEC, em conjunto com os municípios, e tem por objetivo o assessoramento das prefeituras "[...] na elaboração de políticas, planos, programas e projetos setoriais urbanísticos e jurídicos, com vistas à elaboração dos planos diretores municipais, bem como leis de zoneamento, códigos de posturas e obras que possuem impactos ou interesse de âmbito metropolitano, como transportes, habitação, saneamento básico, uso do solo e mobilidade" (IPEA, 2015a, p. 28).

\section{CENÁRIO ATUAL DA RM DE CURITIBA}

A Região Metropolitana (RM) de Curitiba é constituída por 29 municípios em relativo processo de aglomeração urbana, ou seja, os limites políticoadministrativos municipais quase não são percebidos. Assim, consiste em uma malha urbana única que acaba por utilizar conjuntamente os serviços de infraestrutura, com acentuada dependência socioeconômica entre os municípios.

A capital paranaense é a cidade-núcleo, configurando-se como a metrópole 
desempenha na rede urbana brasileira" (KORNIN; CARMO, 2013, p. 87). Dentre os municípios, 14 integram a Área de Concentração da População (ACP), que são "[...] grandes manchas urbanas de ocupação contínua, caracterizadas pelo tamanho e densidade da população, pelo grau de urbanização e pela coesão interna da área, dada pelos deslocamentos da população para o trabalho ou estudo" (IBGE, 2008, p. 11).

Os dados apresentados pelo Censo Demográfico de 2010 indicam a RM de Curitiba como a nona mais populosa do Brasil, com 3.223.836 habitantes. As estimativas para o ano de 2015 apontam para 3.502.804 habitantes com densidade demográfica de 211,24 hab./km². "Em 2010, a RM de Curitiba possuía um grau de urbanização de $91,7 \%$ e cerca de $31 \%$ da população estadual residia na RM. A população do município-núcleo da RM Curitiba, correspondia, em 2010, a $54 \%$ da população metropolitana" (IPEA, 2014, p. 36).

Em termos de território, possui a extensão de $16.581,21 \mathrm{~km}^{2}$, o que corresponde a $11,45 \%$ do território paranaense. Faz fronteira com os Estados de São Paulo, ao norte, e Santa Catarina, ao sul, e configura:

[...] uma aglomeração urbana na porção central, fortemente concentrada, urbanizada, densa, continuamente ocupada, que contrasta [...] com municípios integrantes da Região do Vale da Ribeira, ao norte, marcados por carências econômicas e sociais (FIRKOWSKI; MOURA, 2014, p. 23).

Em função da proximidade física e maior integração com a metrópole, os municípios integrantes da ACP, os mesmos que formam o Núcleo Urbano Central (NUC), consolidam-se "[...] como o espaço que efetivamente abriga a dinâmica metropolitana, diferentemente do recorte legalmente instituído" (IPARDES, 2010, p. 11).A figura 1, visualiza-se o mapa com a localização dos municípios, bem como os limites geográficos, a mancha urbanizada e os municípios que formam o NUC.

A configuração do cenário socioespacial é marcada pela ampliação da fragmentação, heterogeneidade, exclusão social e da segregação espacial metropolitana, o que caracteriza a fase recente da metropolização de Curitiba, na qual persistem os problemas básicos de habitação e de infraestrutura.

A heterogeneidade e fragmentação expressam-se também pelo agrupamento das tipologias dos espaços informais de moradia segundo áreas diferenciadas da metrópole [...] a predominância de loteamentos clandestinos no Norte do aglomerado metropolitano e no extremo Sul de Curitiba, e a concentração de favelas no polo e demais municípios (SILVA, 2014, p. 246 e 247).

No final da década de 2000, a estrutura espacial da metrópole pode ser caracterizada:

i) pela presença simultânea dos movimentos de concentração e dispersão, derivados, respectivamente, da densificação das áreas mais antigas e do surgimento de novas; (ii) pela maior proximidade dos espaços informais de moradia com o núcleo da aglomeração metropolitana, embora também se observe o surgimento de novos em áreas periféricas; e 
(iii) por uma espacialidade mais heterogênea e fragmentada (SILVA, 2014, p. 246).

Os novos espaços informais de moradia também são acompanhados pela diversidade dos perfis econômicos e se consolidam por um padrão que se distancia do centro-periferia.

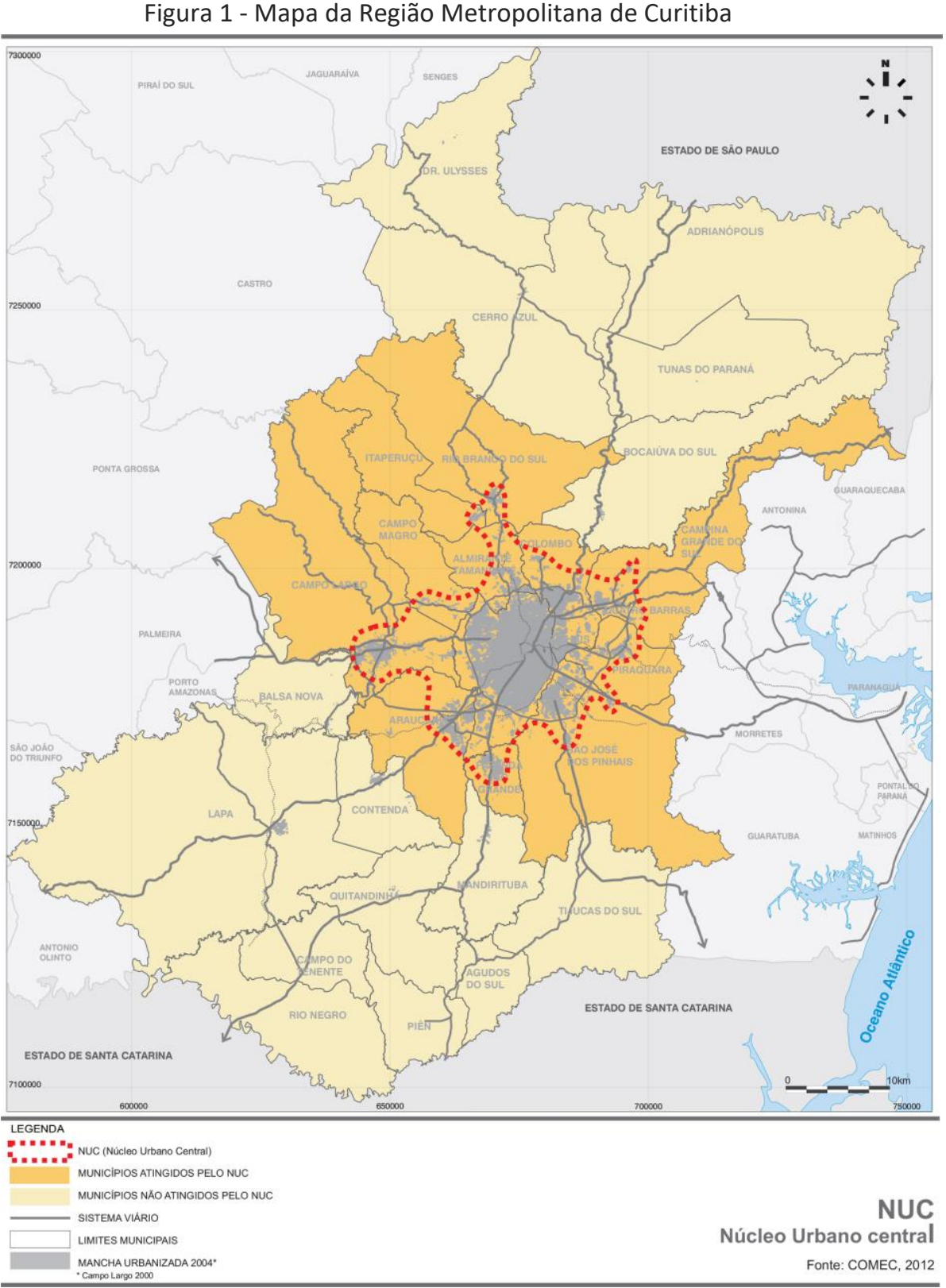

Fonte: Coordenação da Região Metropolitana de Curitiba (COMEC, 2016).

No cenário econômico, segundo Kornin e Carmo (2013, p. 87), "a região se configura como a espacialidade mais concentradora de economia e população do estado do Paraná, e muitos de seus municípios crescem mais que a média estadual [...]". Dados coletados do Instituto Paranaense de Desenvolvimento Econômico e Social (IPARDES) mostram que, no ano de 2013, a economia de ficou entre a maior do estado, respondendo juntos por 35\% do PIB do Paraná. Os 
três primeiros são os únicos municípios do estado que estão entre os cinquenta maiores PIBs municipais do País.

A importância econômica da capital paranaense abrange todo o estado e territórios dos estados vizinhos, consolidando a centralidade regional da RM de Curitiba, o que indica a concentração de população, riqueza, economia, poder, decisão e gestão. Apesar do alto grau de concentração econômica, ao analisar os indicadores socioeconômicos, torna-se evidente a desigualdade existente entre a metrópole e os demais municípios. "Mesmo o enriquecimento de outras cidades da região, como São José dos Pinhais e Araucária, não foi suficiente para aproximá-las do desempenho municipal do polo, portanto, um alto PIB per capita não significa maior desenvolvimento" (IPEA, 2015ạ, p. 18).

Em termos de desenvolvimento humano, no ano de 2013, o Programa das Nações Unidas para o Desenvolvimento (PNUD), em parceria com o Instituto de Pesquisa Econômica Aplicada (IPEA) e a Fundação João Pinheiro, publicou o Atlas do Desenvolvimento Humano (ADH) nas Regiões Metropolitanas, cujo objetivo era apresentar um cenário socioeconômico do País nas duas últimas décadas e, assim, promover um debate acerca do seu desenvolvimento. Os indicadores relacionados à população, à educação, à habitação, à saúde, ao trabalho, à renda e à vulnerabilidade tiveram seus dados extraídos dos Censos Demográficos de 1991, 2000 e 2010.

Neste Atlas, o Índice de Desenvolvimento Humano Municipal (IDHM) da RM de Curitiba apresentava, para o ano de 2010, o indicador de 0,783, classificado como Alto Desenvolvimento Humano. Os valores mais altos de IDHM foram localizados em Unidades de Desenvolvimento Humano (UDHs) concentradas nos municípios de Curitiba $(0,823)$, São José dos Pinhais $(0,758)$ e Pinhais $(0,751)$. Os valores mais baixos de IDHM foram localizados em UDHs concentradas nos municípios de Cerro Azul $(0,573)$ e Doutor Ulysses $(0,546)$.

Como complemento ao IDHM, o Índice de Vulnerabilidade Social (IVS) “... procura dar destaque a diferentes situações indicativas de exclusão e vulnerabilidade social do território brasileiro, em uma perspectiva que vai além da identificação da pobreza entendida apenas como insuficiência de recursos monetários" (IPEA, 2015b, p. 8). É estruturado em três dimensões: infraestrutura urbana; capital humano; e renda e trabalho, que determinam a promoção das condições de bem-estar da população.

A RM de Curitiba apresentava, no ano 2010, o IVS de 0,285 indicando a faixa de baixa vulnerabilidade social. Considerando as dimensões que o compõe, para o mesmo ano, apresentava o índice de 0,405 para Infraestrutura Urbana; 0,341 para Capital Humano; e 0,184 para Renda e Trabalho.

Neste mesmo período, verifica-se que as UDHs com IVS mais baixo se estendem entre os municípios que formam o NUC. Na outra extremidade, os valores mais altos de IVS são encontrados, predominantemente, em UDHs localizadas na porção norte da RM de Curitiba. A figura 2 apresenta os mapas do IDHM e IVS da região, nos quais verifica-se que os maiores IVSs e menores IDHMs estão localizados nos municípios marcados por insuficiências econômicas e sociais e, por consequência, baixa prosperidade social. 


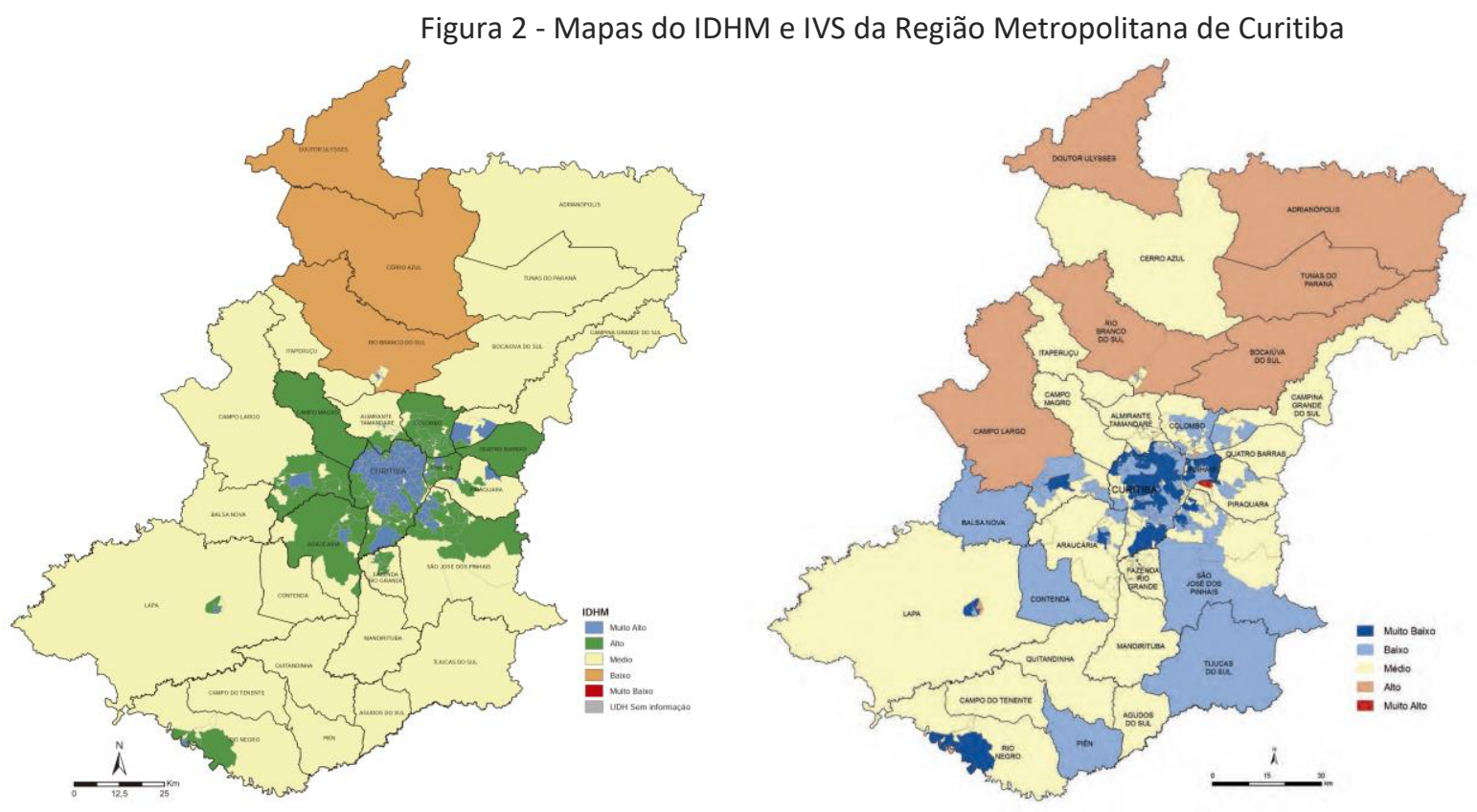

Fonte: Atlas do Desenvolvimento Humano nas Regiões Metropolitanas Brasileiras (IPEA, 2014, p. 35). Atlas da Vulnerabilidade Social nas Regiões Metropolitanas Brasileiras (IPEA, 2015b, p. 61).

Os contrastes espaciais, econômicos e sociais existentes entre os municípios da RM de Curitiba refletem, diretamente, nas administrações municipais. Os servidores públicos são responsáveis pelos processos de planejamento, implementação e execução das políticas públicas. Portanto, é imprescindível que tais servidores estejam preparados para compreender as diversas instâncias de planejamento, assim como a importância da cooperação entre os Entes Federados. Pensar a administração municipal de forma integrada, colaborativa e participativa, entre os municípios e metrópole, é fundamental considerando a interdependência de fluxos, políticas públicas, economia e infraestrutura urbana.

\section{FORMAÇÃO PROFISSIONAL DOS SERVIDORES MUNICIPAIS DA REGIÃO METROPOLITANA (RM) DE CURITIBA}

A pesquisa Fortalecimento Institucional e Qualificação da Gestão Municipal no Estado do Paraná, organizada pelo IPARDES e coordenada pela Diretoria de Estudos Regionais e Urbanos do IPEA, no ano de 2010, foi realizada em 40 municípios do Estado do Paraná. Dentre estes, que refletem 10\% dos municípios do estado, seis pertencem a RM de Curitiba.

Os resultados da pesquisa, no que se refere à gestão setorial "[...] ressaltam a existência de maior fragilidade em relação à implantação e à implementação dos instrumentos de gestão considerados característicos da moderna gestão pública" (RAGGIOet al, 2011, p. 83). Neste sentido, para que a Administração Pública se torne mais sólida e comprometida, algumas mudanças se fazem necessárias, como "[...] formação de servidores públicos, planejamento de investimento, participação e controle social, observadas como frágeis ao longo da análise setorial, devem ser objeto de políticas públicas voltadas para a consolidação da gestão municipal" (RAGGIO et al, 2011, p. 83). 
Com relação à formação de servidores públicos, a pesquisa não mostra detalhes, entretanto, evidencia a fragilidade institucional com relação ao investimento na capacitação dos servidores, na oferta e programação de cursos e no atendimento de demandas específicas. Percebe-se que "[...] os cursos são dirigidos, fundamentalmente, para a formação e treinamento que viabilizam o desempenho dos serviços básicos ou de rotinas [...] treinamentos para a incorporação de instrumentos novos, como a informática, ou para a absorção das legislações que informam para preenchimentos de matérias e documentos" (RAGGIO et al, 2011, p. 84). Partindo do pressuposto de que a formação e o desenvolvimento profissional dos servidores públicos são fundamentais para os processos de concepção e operacionalização das políticas públicas, destaca-se, na pesquisa, a necessidade do estabelecimento de diálogos intersetoriais, potencialização do conhecimento e investimento em ações concretas.

\begin{abstract}
O desafio é dotá-los de instrumentos que permitam a leitura das questões sociais, econômicas e ambientais que marcam o desenvolvimento dos municípios em que habitam e trabalham. Não adianta a produção de informações se os servidores não as incorporam na sua percepção da sociedade. Esta perspectiva pretende reforçar a intenção da realização de cursos de formação integral, de saberes multidisciplinares que os habilitem para a leitura da realidade na construção de soluções públicas que consolidem a cidadania (RAGGIO et al, 2011, p. 84).
\end{abstract}

Desta maneira, é fundamental que o servidor esteja preparado não apenas na perspectiva técnica mas com uma visão crítica e ampla acerca dos significados de uma política pública. É necessário que o servidor esteja consciente do seu valor, da sua função e do seu papel perante a sociedade.

\title{
PROGRAMA DE INTEGRAÇÃO E COMPARTILHAMENTO DE CONHECIMENTO ENTRE SERVIDORES MUNICIPAIS DE CURITIBA E REGIÃO METROPOLITANA
}

O Instituto Municipal de Administração Pública (IMAP) ${ }^{7}$, autarquia da Prefeitura Municipal de Curitiba (PMC), tem como missão "Desenvolver, disseminar e implementar instrumentos e metodologias de aperfeiçoamento contínuo da Administração Pública, contribuindo para a transformação da Sociedade" (IMAP, 2015). É por meio da Escola de Administração Pública (EAP) que se formam e desenvolvem profissionalmente servidores municipais "[...] para agirem de modo crítico, autônomo e socialmente responsável" (IMAP, 2015, p. 3). A atribuição da EAP é "Promover formação e pesquisa para o desenvolvimento da Administração Pública, da cidade e dos cidadãos, de forma intersetorial e participativa, contribuindo para a efetividade das políticas públicas" (IMAP, 2015).

No ano de 2013, em uma perspectiva da construção de uma governança integrada e participativa, com vistas a uma maior integração, racionalização e visão metropolitana do processo de desenvolvimento regional, a PMC promove uma parceria entre o IMAP e a SMAM. Esta parceria tem o propósito de "[...] fomentar a integração dos municípios no desenvolvimento do

\footnotetext{
Página |377

${ }^{7}$ Lei Municipal nํㅜ 2.347/1963.
} 
território,fortalecimento regional e potencialização dos resultados das políticas públicas" (IMAP, 2015, p. 16).

Dentro desta premissa, é elaborado o Programa de Integração e Compartilhamento de Conhecimento entre Servidores Municipais de Curitiba e Região Metropolitana, que tem por objetivo:

Contribuir para a formalização de parcerias que possibilitem o compartilhamento de conhecimento, intercâmbio sobre temas relacionados aos municípios, troca de experiências, reuniões técnicas e práticas de trabalho para o fortalecimento institucional local e regional, bem como o desenvolvimento de todo o território metropolitano. (IMAP, 2015, p. 16).

Seguiram-se as seguintes etapas de elaboração

a) consolidação da parceria e planejamento para implementação, execução e acompanhamento das etapas seguintes;

b) divulgação do Programa para as Prefeituras da RM de Curitiba;

c) aplicação de um questionário utilizado como coleta de dados particularizados, com o propósito de subsidiar e produzir instrumentos para uma análise da realidade das prefeituras da RM de Curitiba, no que diz respeito ao desenvolvimento de pessoas, levantamento de recursos materiais e de infraestrutura necessários para as ações de integração e compartilhamento de conhecimento. Para esta etapa, foi desenvolvido um Sistema informatizado, cujo acesso foi disponibilizado para todas as prefeituras por meio de senhas individuais. O questionário foi respondido por meio deste Sistema e os dados obtidos foram compilados, tabulados e analisados, resultando na elaboração de um diagnóstico, que serviu de subsídio para o mapeamento das ações. Também foram realizadas visitas técnicas em cinco prefeituras, escolhidas aleatoriamente, dos seguintes municípios: Contenda, Lapa, Pinhais, Quitandinha e São José dos Pinhais;

d) formação de uma Rede de Articuladores ${ }^{8}$ composta por servidores, representantes das prefeituras da RM de Curitiba, que foram preparados por meio de seminários e oficinas para atuarem em conjunto com os Articuladores da PMC, no planejamento, execução e avaliação do Plano de Formação e Desenvolvimento Profissional ${ }^{9}$, desenvolvido pelo IMAP, para os servidores de Curitiba e RM;

\footnotetext{
${ }^{8}$ Servidores públicos vinculados aos órgãos/entidades da PMC e das prefeituras da RM de Curitiba que realizam, em conjunto com o IMAP, o planejamento, execução e avaliação do Plano de Formação e Desenvolvimento Profissional. Página | 378

9 Documento elaborado anualmente pela EAP, concretizado e disseminado por meio do Catálogo de Cursos do IMAP
} 
e) formalização de parcerias para a execução das ações de integração e compartilhamento de conhecimento, dentre as quais pode-se citar a Controladoria Geral da União (CGU); a Escola de Administração Fazendária (ESAF); o Serviço Social da Indústria (SESI); o Instituto Paranaense de Desenvolvimento Econômico e Social (IPARDES); o Lincoln Institute; o Ministério das Cidades; e a Universidade Federal do Paraná (UFPR). Além de algumas entidades e órgãos da PMC, como: Fundação de Ação Social (FAS); Gabinete de Gestão Integrada (GGI-M); Instituto Municipal de Turismo (CTUR); Instituto de Pesquisa e Planejamento Urbano de Curitiba (IPPUC); Procuradoria Geral do Município (PGM); Secretaria do Governo Municipal (SGM); Secretaria Especial dos Direitos da Pessoa com Deficiência (SEDPD); Secretaria Municipal da Educação (SME); Secretaria Municipal de Defesa Social (SMDS); Secretaria Municipal de Finanças (SMF); Secretaria Municipal de Planejamento e Administração (SEPLAD); Secretaria Municipal de Recursos Humanos (SMRH); e Secretaria Municipal da Saúde (SMS). E, também, a busca de patrocínio recebido por meio da Itaipu Binacional.

Do total de municípios que compõem a RM de Curitiba, 26 prefeituras aderiram ao Programa, cuja legislação de referência é o Decreto Municipal no 487, de 13 de maio de 2016, que regulamenta o Sistema Integrado de Formação e Desenvolvimento Profissional dos Servidores e Agentes Públicos Municipais.

Para a implementação do Programa, foi realizado um levantamento das ações de integração e compartilhamento de conhecimento, no qual cada articulador verificou a necessidade da sua Administração Municipal, considerando uma previsão para o período compreendido entre os anos de 2013 e 2016. Após este levantamento, foi elaborado o projeto de cada uma das ações, considerando o número de servidores a serem capacitados, o número de turmas necessárias, a infraestrutura para a capacitação e a parceria a ser instituída.

Tais ações, que integram o Plano de Formação e Desenvolvimento Profissional, compreendem as seguintes áreas de conhecimento: Abordagem no Atendimento ao Cidadão para profissionais dos serviços de saúde, Atendimento ao Cidadão, Comunicação Escrita Oficial, Contabilidade Pública, Contratos Administrativos, Desenvolvimento de Roteiros Turísticos, Elaboração de Projetos, Financiamento do Desenvolvimento Urbano, Fiscalização de Tributos Municipais (ISS, IPTU, ITBI, ISSQN), Gestão Arquivística de Documentos, Gestão Integrada em Segurança Pública, Inclusão Digital, Lei de Acesso à Informação, Licitação e Contratos, Mobilização de Recursos, Negociação e Mediação de Conflitos, Pessoas com Deficiência, Planejamento Urbano, Política sobre Drogas e Sistema Metropolitano de Georreferenciamento.

Importante ressaltar que, algumas ações desenvolvidas vão além deste levantamento e contemplam os seguintes temas: Administração Pública Deliberativa, Aspectos Práticos do Acesso à Informação Pública, Estatuto da Metrópole, Fortalecimento do Papel dos Conselhos, Fiscalização e Desenvolvimento de Técnicas e Habilidades de Proteção à Comunidade, Gestor do Contrato. 
Nos três anos de vigência do Programa, analisados neste artigo, houve um aumento da participação dos servidores municipais da RM de Curitiba nas ações desenvolvidas, conforme demonstrado no Quadro 3. Considera-se o quantitativo de ações de formação e desenvolvimento profissional e o número de participantes certificados. Além das ações desenvolvidas especificamente para os servidores da RM, também foram oferecidas vagas nas ações realizadas para os servidores da PMC, classificadas como aproveitamento de vagas.

Quadro 3 - Ações de Formação e Desenvolvimento Profissional e participantes certificados.

\begin{tabular}{|c|c|c|c|c|c|c|}
\hline \multicolumn{1}{|c|}{\begin{tabular}{c|c|c|} 
QUANTITATIVO DE \\
DESCRIÇÃO
\end{tabular}} & \multicolumn{2}{|c|}{$\begin{array}{c}\text { PARTICIPANTES } \\
\text { CERTIFICADOS }\end{array}$} \\
\hline $\begin{array}{c}\text { Plano de Formação e Desenvolvimento Profissional } \\
\text { (aproveitamento de vagas) }\end{array}$ & 2013 & 2014 & 2015 & 2013 & 2014 & 2015 \\
\hline Parcerias & 20 & 23 & 27 & 297 & 227 & 227 \\
\hline TOTAL & 08 & 17 & 16 & 302 & 650 & 969 \\
\hline
\end{tabular}

Fonte: Sistema Aprendere ${ }^{10}$.

O número de vagas aproveitadas pelos servidores da RM foi expressivo nos três anos analisados, considerando que todas as ações foram realizadas em Curitiba. Entretanto, o número de certificações mais significativo está nas ações desenvolvidas com as parcerias. Estas ações foram planejadas especificamente para os servidores da RM, contemplando os temas solicitados no levantamento das ações de integração e compartilhamento de conhecimento realizado no primeiro ano do Programa.

A maioria destas ações aconteceram nos próprios municípios, escolhidos aleatoriamente e contemplando aqueles mais distantes de Curitiba. As turmas eram compostas, em sua maioria, por servidores do município sede e, também, dos municípios mais próximos. Desta forma, possibilitou-se a participação de alguns municípios que, dada a condição econômica e localização, quase nunca enviaram servidores para cursos em Curitiba.

O número de ações realizadas com parcerias também evoluiu no decorrer do período, pois a medida que as necessidades de formação eram identificadas, novas parcerias eram consolidadas. Algumas instituições, inclusive, ao tomar ciência do Programa, procuravam pela EAP para oferecer a parceria, dada a importância em levar novos conhecimentos para os servidores da RM.

Comparando os resultados, as certificações mantiveram uma constante, o que evidencia que as ações realizadas em parcerias atingiram com êxito os servidores da RM. Os municípios que obtiveram maior número de servidores certificados são aqueles que fazem parte do NUC, no caso, São José dos Pinhais, Araucária, Pinhais e Fazenda Rio Grande. Os que menos participaram foram os municípios mais distantes e, por consequência, mais carentes do ponto de vista econômico.

\footnotetext{
Página $\mid 380$
}

${ }^{10}$ Sistema de Informação Informatizado/IMAP. 


\section{CONSIDERAÇÕES FINAIS}

Este artigo teve a finalidade de apresentar os arranjos institucionais, bem como o atual cenário da RM de Curitiba, com vistas à caracterização do território em seus aspectos espacial, econômico e social. Igualmente, a formação e o desenvolvimento do servidor municipal, como parte do processo de fortalecimento das administrações municipais e gestão do território, tendo em vista a responsabilidade deste na formulação e execução das políticas públicas.

Com relação à análise da capacidade de uma Escola Metropolitana de Administração Pública em oportunizar ao servidor uma formação adequada, compreendendo a necessidade de uma atuação integrada, com visão crítica e ampla acerca dos significados de uma política pública, entende-se que os resultados apresentados pelo Programa de Integração e Compartilhamento de Conhecimento entre Servidores Municipais de Curitiba e Região Metropolitana são pequenos se comparados com a abrangência do território. Entretanto, se comparados com a evolução da participação dos servidores nas ações de formação e áreas de conhecimento contempladas, percebe-se que a Escola proporciona condições favoráveis para que o servidor tenha acesso a uma formação adequada.

Por fim, considera-se de extrema importância a atuação de uma Escola de Administração Pública com abrangência metropolitana, tendo em vista a necessidade de integração entre os municípios da região. É mister a formação dos servidores municipais, de modo que tenham condições plenas de identificar os problemas de seu município, relacionar com os problemas enfrentados pelos municípios vizinhos e, assim, criar um ambiente sinérgico e propício para a gestão do território. 


\title{
Territoriality and server formation in the context of metropole
}

\begin{abstract}
This article aims to present the institutional arrangements and current scenario of the Metropolitan Region of Curitiba, as well as to analyze if a Metropolitan School of Public Administration would be able to provide the server with adequate training and with a view to an integrated, critical vision And broad about the meanings of a public policy. For that, the methodology used is descriptive and exploratory, with a qualitative approach. Its reasoning was based on a case study and the source of data collection, through the use of documents. The analyzed school is the one maintained by the Municipal Institute of Public Administration, autarchy of the Municipality of Curitiba, through the Program of Integration and Sharing of Knowledge between Municipal Servants of Curitiba and Metropolitan Region. The main results show that the performance of a School of Public Administration is extremely important given the metropolitans cope and the need for integration among the municipalities of the region.
\end{abstract}

KEY WORDS: Territory management. Training of servers. School of Public Administration. 


\section{REFERÊNCIAS}

\section{BRASIL.PRESIDENCIA DA REPÚBLICA. Constituição da República Federativa do} Brasil de 1988. Disponível em:

<http://planalto.gov.br/ccivil_03/Constituicao/Constituicao.htm>. Acesso em: 08 abr. 2016.

Lei Complementar Federal n 14, de 08 de junho de 1973:

estabelece regiões metropolitanas de São Paulo, Belo Horizonte, Porto Alegre, Recife, Curitiba, Belém e Fortaleza. Disponível em:<http://www.planalto.gov.br/ccivil_03/leis/LCP/Lcp 14.htm>. Acesso em 18 ago. 2016.

. Lei Federal $\mathbf{n}$ 13.089, de 12 de janeiro de 2015:institui o Estatuto da Metrópole: altera a Lei no 10.257, de 10 de julho de 2001: e dá outras providências. Disponível em: <http://www.planalto.gov.br/ccivil_03/_Ato2015-2018/2015/Lei/L13089.htm>. Acesso em: 18 ago. 2016.

Lei Federal n 6.766, de 19 de dezembro de 1979: dispõe sobre o parcelamento do solo urbano e dá outras Providências. Disponível em: <http://www4.planalto.gov.br/legislacao>. Acesso em: 26 ago. 2016.

CURITIBA (Município). CAMARA MUNICIPAL. Decreto Municipal $\mathbf{n}$ 487, de 13 de maio de 2016: dispõe sobre a instituição e as atribuições do sistema integrado de formação e desenvolvimento profissional dos servidores e agentes públicos municipais. Disponível em:

$<$ http://legisladocexterno.curitiba.pr.gov.br/AtosConsultaExterna.aspx>. Acesso em: 28 ago. 2016.

..Decreto Municipal $\mathrm{n}$ 716, de 30 de setembro de 1994: cria escola de administração pública: cidade de Curitiba. Disponível em: <http://www.imap.curitiba. pr.gov.br/wpcontent/uploads/2014/PDF/Decretos/IMAP/D0716.1994.pdf>. Acesso em: 14 ago. 2016.

Lei Municipal n 2.347, de 1963: dispõe sobre a criação do Instituto Municipal de Administração Pública, em seu capítulo XI, artigo 54 ao artigo 58. Disponível em: <https://leismunicipais.com.br/a/pr/c/curitiba/leiordinaria/1963/234/2347/lei-ordinaria-n-2347-1963>. Acesso em: 13 ago. 2016.

Lei Municipal n 857 de 17 de maio de 2005: dispõe sobre a estrutura organizacional, níveis hierárquicos, orgânicos e funcionais da Secretaria Municipal de Assuntos Metropolitanos. Disponível em: 
content/uploads/2014/PDF/Decretos/SMAM/DO\%20857.2005.pdf>. Acesso em: 25 ago. 2016.

PREFEITURA. SECRETARIA MUNICIPAL DE ASSUNTOS METROPOLITANOS. Disponível em:<http://www.curitiba.pr.gov.br/conteudo/equipe-smam/24>. Acesso em: 18 ago. 2016.

FIRKOWSKI. O. L. C. de F. (org.); MOURA. R. (org.). Curitiba: transformações na ordem urbana. Rio de Janeiro: Letra Capital: Observatório das Metrópoles, 2014.

INSTITUTO BRASILEIRO DE GEOGRAFIA E ESTATÍSTICA. Região de influência das cidades: REGIC 2007. Rio de Janeiro: IBGE, 2008. Disponível em:

<http://www.mma.gov.br/estruturas/PZEE/_arquivos/regic_28.pdf>. Acesso em: $21 \mathrm{abr} .2016$.

INSTITUTO MUNICIPAL DE ADMINISTRAÇÃO PÚBLICA. Projeto Político Pedagógico. Curitiba: IMAP, 2015. Disponível em:

$<$ http://redeescolas.enap.gov.br/wpcontent/uploads/2015/12/XI_ENEG_Painel_PerfilEG_IMAP_SP.pdf >. Acesso em: 21 mar. 2016.

Conheça o IMAP: institucional. Disponível em:

<http://www.imap.curitiba.pr.gov.br>. Acesso em: 14 ago. 2016.

Conheça o IMAP: escola de administração pública. Disponível em: <http://Imap.curitiba.pr.gov.br>. Acesso em: 14 ago. 2016.

INSTITUTO PARANAENSE DE DESENVOLVIMENTO ECONÔMICO E SOCIAL. Dinâmica urbana dos Estados: Estado do Paraná. Disponível em: <http://www.ipardes.gov.br/biblioteca/docs/Dinamica_Urbana_dos_Estados_Par ana.pdf>. Acesso em: 25 ago. 2016.

Fortalecimento institucional e qualificação da gestão municipal: Estado do Paraná. Brasília: IPARDES, 2011. Disponível em:

<http://www.ipardes.gov.br/biblioteca/docs/ipardes_ipea_fortalecimento_qualif ic_gestao_municipal.pdf>. Acesso em: 21 mar. 2016.

Paraná em números. Disponível em: <http://www.ipardes.gov.br/index. php?pg_conteudo=1\&cod_conteudo=1>. Acesso em: 25 ago. 2016.

INSTITUTO DE PESQUISA ECONÔMICA APLICADA. Atlas do desenvolvimento 
<http://www.ipea.gov.br/agencia/images/stories/PDFs/livros/livros/141125_atla s_curitiba>. Acesso em: 18 ago. 2016.

(IPEA, 2015a). Governança metropolitana no Brasil: relatório de pesquisa: caracterização e quadros de análise comparativa da governança metropolitana no Brasil: arranjos institucionais de gestão metropolitana (Componente 1): região metropolitana de Curitiba. Rio de Janeiro: IPEA, 2015. Disponível em:

<http://www.ipea.gov.br/redeipea/images/pdfs/governanca_metropolitana/150 909_relatorio_arranjos_igm_rm_curitiba.pdf>. Acesso em: 21 mar. 2016.

.(IPEA, 2015b) Atlas da vulnerabilidade social nas regiões

metropolitanas brasileiras. Disponível em:

<http://www.ipea.gov.br/portal/images/stories/PDFs/151008_atlas_re gioes_metropolitanas_brasileiras.pdf>. Acesso em: 18 ago. 2016.

KORNIN. T.; CARMO. J. C. B. do. 0 arranjo institucional de gestão na região metropolitana de Curitiba: 40 anos de regiões metropolitanas no Brasil. Brasília: IPEA, 2013. Disponível em:

<http://www.ipea.gov.br/portal/images/stories/PDFs/livros/livro_40_anos_regio es_metropolitanas_vol01.pdf>. Acesso em: 12 mar. 2016.

PARANÁ. ASSEMBLEIA LEGISLATIVA. Decreto estadual no 1.660, 21 de outubro de 1992: atribuição de gerenciamento do sistema de transporte coletivo da região metropolitana de Curitiba, à Coordenação da Região Metropolitana de Curitiba (COMEC). Disponível em:

<http://www.legislacao.pr.gov.br/legislacao/pesquisarAto.do?action=iniciarProce sso\&retiraLista=true\&site=1>. Acesso em: 26 ago. 2016.

Lei estadual n. 11.027, de 28 de dezembro de 1994: transforma a coordenação da região metropolitana de Curitiba em autarquia e adota outras providências. Disponível em:

<https://www.emplasa.sp.gov.br/Cms_Data/Sites/EmplasaDev/Files/fnem/arqui vos/Legisla\%C3\%A7\%C3\%A30\%20Regi\%C3\%B5es\%20Metropolitanas/Parana/Lei \%20n\%C2\%BA\%2011.027\%20RM\%20CURITIBA.pdf>. Acesso em: 26 ago. 2016.

.Lei estadual n. 11.096, de 16 de maio de 1995: altera o parágrafo único, do artigo 2, da lei n 11.027, de 29 de dezembro de 1994. Disponível em: <http://www.legislacao.pr.gov.br/legislacao/pesquisarAto.do?action=iniciarProce sso\&retiraLista=true\&site=1>. Acesso em: 26 ago. 2016.

.Lei estadual n. 12.125, de 22 de abril de 1998: dá nova redação ao parágrafo único, do artigo 2, da lei n 11.027, de 29 de dezembro de 1994. Disponível em: 
<http://www.legislacao.pr.gov.br/legislacao/pesquisarAto.do?action=i niciarProcesso\&retiraLista=true\&site=1>. Acesso em: 26 ago. 2016.

.Lei estadual no 13.512, de 21 de janeiro de 2002: dá nova redação ao parágrafo único do artigo 2 , da Lei n. 11.027, de 29 de dezembro de 1994. Disponível em:

$<$ http://legislacao.pr.gov.br/legislacao/pesquisarAto.do?action=iniciar Processo\&retiraLista=true\&site=1>. Acesso em: 26 ago. 2016.

.Lei estadual n 139, de 12 de dezembro de 2011:altera o parágrafo único do artigo 2, da Lei no 11.027, de 29 de dezembro de 1994, incluindo os municípios de Piên, Campo do Tenente e Rio Negro. Disponível em: $<$ http://www.legislacao.pr.gov.br/legislacao/pesquisarAto.do?action=iniciarProce sso\&retiraLista=true\&site=1>. Acesso em: 26 ago. 2016.

.Lei estadual n 12.248, de 31 de julho de 1998: cria o sistema integrado de gestão e proteção dos mananciais da RMC. Disponível em: $<$ http://www.legislacao.pr.gov.br/legislacao/pesquisarAto.do?action=iniciarProce sso\&retiraLista=true\&site=1>. Acesso em: 26 ago. 2016.

Lei estadual $\mathbf{n}$ 6.517, de 2 de janeiro de 1974: institui a Coordenação da Região Metropolitana de Curitiba (COMEC). Disponível em: <http://www.legislacao.pr.gov.br/legislacao/pesquisarAto.do?action=iniciarProce sso\&retiraLista=true\&site=1>. Acesso em: 26 ago. 2016.

. SECRETARIA DO DESENVOLVIMENTO URBANO. Coordenação da região metropolitana de Curitiba. Disponível em: <http://www.comec.pr.gov.br/arquivos/File/Mapas2013/RMC_2013_NUC.pdf>. Acesso em 14 ago. 2016.

SILVA. M. N. da.Produção dos espaços informais de moradia e tendências de organização socioespacial do território na metrópole de Curitiba: Curitiba: transformações na ordem urbana. Rio de Janeiro: Letra Capital: Observatório das Metrópoles, 2014.

VELOSO, João F. A.et al. Gestão municipal no Brasil: um retrato das prefeituras. Brasília, DF: IPEA, 2011. Disponível em: <http://www.ipea.gov.br/portal/images/stories/PDFs/livros/livros/livro_gestaom unicipal.pdf>. Acesso em: 23 fev. 2016. 
Recebido: 28 mai. 2017

Aprovado: 03 ago. 2017

DOI: $10.3895 /$ rbpd.v6n3.5792

Como citar: TRAUB, A.; MYSZCZUK, A. P. Territorialidade e formação do servidor no contexto da metrópole. R. bras. Planej. Desenv., Curitiba, v. 6, n. 3, p. 368-387, set./dez. 2017. Disponível em: $<$ https://periodicos.utfpr.edu.br/rbpd>. Acesso em: XXX.

\section{Correspondência:}

Andrea Traub

Av. Sete de Setembro, 3165 - Rebouças, Curitiba - PR

Direito autoral: Este artigo está licenciado sob os termos da Licença CreativeCommons-Atribuição 4.0 Internacional.

\section{(c) (1)}

